\title{
Critical Fiber Length of Mendong Fiber in Epoxy Matrix Composite
}

\author{
Heru Suryanto \\ Departement of Mechanical Engineering, \\ Faculty of Engineering, Universitas Negeri Malang \\ Malang, Jawa Timur, Indonesia \\ E-mail: heru.suryanto.ft@um.ac.id
}

\begin{abstract}
- the disposal of synthetic fiber is very difficult to be degraded and cause problems in the environment. The renewable materials have potency as an alternative material for replacing the synthetic material in the composite product. This study was to determine the critical fiber length of mendong fiber embedded in the epoxy composite. The methods were the extraction of mendong fiber from straw, pull out test methods, and morphology analysis of pull out a test using scanning electron microscope. Results show that mendong fiber had a shear strength of 11 MPa and indicated a critical fiber length of 630 $\mu \mathrm{m}$. The low critical fiber length of mendong embedded in epoxy matrix indicate good adhesion properties of mendong in an epoxy matrix. It recommends that mendong fibers can apply as reinforcement in the epoxy composite in the form of short fiber.
\end{abstract}

Keywords: critical fiber length, epoxy, mendong fiber; pull out test, shear strength

\section{INTRODUCTION}

Polymeric technology for environmental sustainability is an important issue to use the material from renewable resources for changing the synthetic material. In various ways, the synthetic fibers have many advantages to fulfil human being needs. However, disposal of synthetic fiber is very durable and difficult to be degraded. It creates problems in the surrounding environment. It is required an alternative manner to secure sustainable environment. The renewable materials have the ability to be applied as an alternative material for replacing the synthetic material in the manufactured product.

In the recent years, natural fibers have been used in many applications as it has many advantages. The advantages of natural fiber are abundantly available, easy to be separated, low price, biodegradable, renewable, low density, and no hazard for healthy [1][2]. Polymeric products based on green material from agricultural stock are competing with synthetic products. The forecast products from bio-based feedstock increase from $12 \%$ in 2010 to about $25 \%$ in 2030 [3]. The bulk chemicals production obtained from the renewable resources was estimated achieve 113 million tons or represent $38 \%$ production in all organic chemical by 2050 [4].

Mendong (Fimbristylis globulosa) is a type of grass that grows in wetland areas and usually grows up to more than 100 $\mathrm{cm}$ in length. Traditionally, the mendong straws have been used for rope, mats, and other product like baskets, furniture, and handbags [5]. The mendong grass has the potency as fiber sources because of the production of mendong estimated 14,000 tons every year in Java, Indonesia [6]. It needs an effort to transform the fiber application fields from a conservative product to a progressive product by using it as reinforcement in the composites system.

Beside the interfacial shear strength, the important aspect of natural fibers as reinforcement in polymer matrix composites is the length of the fiber. The long fibers can be applied, but they have to be severely bundled, and this can resist the free flow of resin between the fibers' interstice. Poor wetted fiber regions cause defects that promote premature failure of polymer composites. Therefore, in many instances, the use of short fibers is preferred [7]. The short fiber reinforced composites was used in wide spread application from bath tubs to interior structures in trains, cars, or even aircraft that manufactured using thermoplastic or thermoset resins as the matrix. This study was to determine the critical fiber length of mendong fiber as the parameter needs to be considered in order to fully use the short mendong fibers in polymer composite.

\section{METHODS}

\section{A. Material}

The research used mendong straw samples collected from the region of Wajak, Jawa Timur, Indonesia. Mendong straw was selected in the range of 5 to 6 months old planting. The mendong fibers contain $20.2 \%$ hemicellulose, $72.14 \%$ cellulose, $3.44 \%$ lignin, and degree of crystalline of $70.7 \%$ [8] Mendong fiber has both tensile strength and stiffness modulus were of $452 \mathrm{MPa}$ and $17 \mathrm{GPa}$, respectively [6].

The polymer matrix was diglycidyl ether of bisphenol-A (DGEBA) (brand name Eposchon, PT. Justus Kimia Raya, Surabaya, Indonesia). The curing agent was a modified cycloaliphatic amine containing mainly of 3-aminomethyl3,5,5-trimethylcyclohexylamine (EPH 555, PT. Justus Kimia Raya, Surabaya, Indonesia) [9].

\section{B. Fiber Extraction}

Mendong fibers were obtained using mechanical methods. The fresh mendong straws were cut in length of $60 \mathrm{~cm}$ from the 
straw base. Mendong straw was repeatedly beaten using a plastic hammer, and then, cleaned by water. Mendong straw was chopped, cleaned and immersed in the water as long as a week. Mendong fibers were retrieved, cleaned and dried in the room temperature. Mendong fibers were immersed into $\mathrm{NaOH}$ solution with a concentration of $5 \%$ at room temperature for 2 hours and then washed with water for five times. Dried it at room temperature, wrapped and kept it for analysis in a dry container [10].

\section{Fiber Pull-out Test}

The single fiber pull-out test was conducted for determining the interfacial shear strength of mendong fiber in the epoxy matrix, refer to Suryanto methods [9]. Pull-out tests conducted for ten specimens in a fiber tensile test device with maximum force $5 \mathrm{~N}, 1 \mathrm{mN}$ resolution and a tension speed of $3.5 \mathrm{~mm} / \mathrm{min}$ at room temperature. The pull-out test of single fiber embedded in the epoxy composite was shown in Fig. 1.

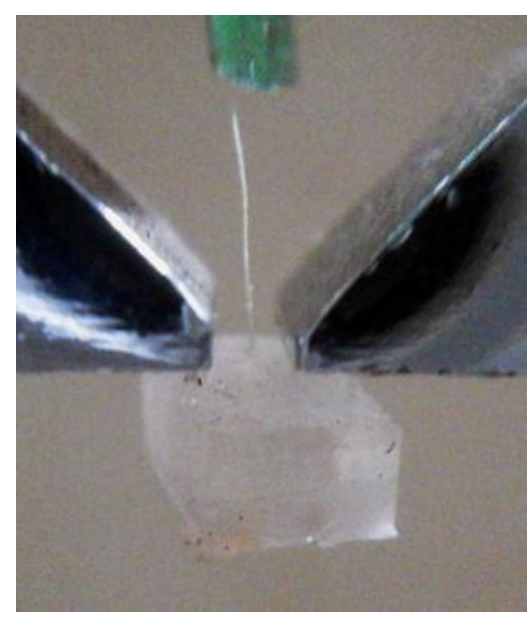

Fig. 1. Single fiber pull out test

Mechanism of stress transfer from fiber to the matrix is explained by Fig.2. Fig 2A shows the load (F) occurring in the fibers embedded in the matrix with L length. Evolution of transferred load in the interface fiber-matrix is shown in Fig 2B. The minimum length that able to transfer external load indicate the critical fiber length $\left(l_{c}\right)$.

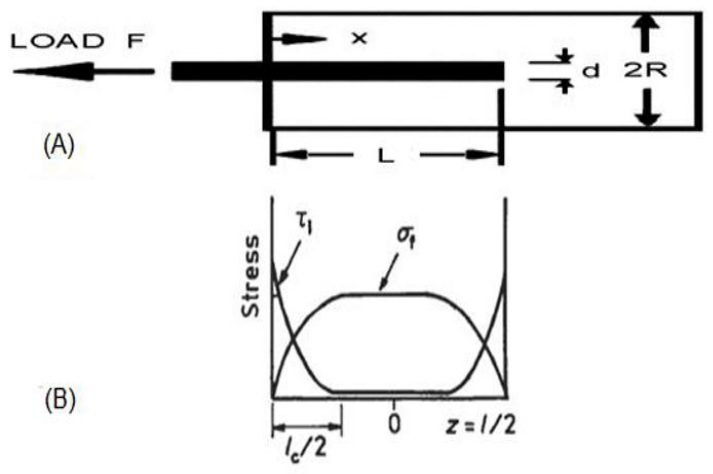

Fig. 2. Stress transfer in pull out test [11] [12]
Interfacial shear strength formulation was expressed by equation (1) and (2) [11] [12]:

$$
\tau=\frac{F}{\pi \cdot d \cdot L_{t}}
$$

where: F: maximu m tensile load cause debonding of fiber; $d$ : fiber diameter; Lt: embedded length of the fiber.

By using the shearstress, it can obtain an aspect ratio (lc/d) as an indicator of the strength of the fiber-matrix bonding [13]:

$$
\frac{l_{c}}{d}=\frac{\sigma_{f}}{4 \tau}
$$

where $\sigma_{f}$ fiber strength; $d$ : diameter; $1_{c}$ : critical fiber length

\section{Scanning Electron Microscope/SEM}

The morphological structure of the debonding matrix was observed using Scanning Electron Microscope (FEI, InspectS50 type). The specimen was coated with gold with a thickness of $10 \mathrm{~nm}$, after that, it observed in the SEM.

\section{RESULT AND DISCUSSION}

The pull-out test is performed on single fibers embedded in the epoxy matrix. The pull-out test is performed until the fiber is debonded from the epoxy. The result of pull out test to obtain the critical length of mendong fiber in the epoxy matrix was shown in Fig. 2. Fig 2A shows mendong fiber was embedded in the epoxy matrix and a good adhesion between fiber and matrix indicated by a concave meniscus in the bottom of fiber. After pull out test, the fiber was debonded and leaving a hole in the epoxy matrix. It shows that interface bond between fiber and matrix has not able to resist load applied to the fiber (Fig 2B). After interface bond was higher than fiber strength, the fiber was a fracture (Fig 2C).

The result of measurement of shear stress and critical fiber length was shown in Table 1. The interfacial shear stress is an indicator of the effectiveness of the bond between fiber and matrix. The interfacial shear stress of mendong fiber in the epoxy matrix composite is $11 \mathrm{MPa}$. This result was lower than banana, hemp, flax and ramie fiber but higher than cotton and piassava fiber. Higher interfacial shear stress indicate good interaction between fiber and epoxy. Interaction of fiber and matrix was influenced by the crystallinity of polymer [13], fiber surface topography [14], and coupling agent like silane [15], glutarate dialdehyde [16], maleate [17], and surface free energy and polar component [18].

Critical length of fiber is the minimum fiber length is required to transfer the load until fiber fail. Critical length fiber is an indicator for the ability of interphase to transfer load in the composite fiber. The shorter the size of the fibers are embedded in the matrix but still provides the fiber-matrix shear strength then transfer the load will be more effective in the composite. The smaller the value of the aspect ratio of the fiber interface shear forces will be better [14]. In this test result, a critical length fiber mendong without treatment embedded in an epoxy matrix is equal to $0.630 \mathrm{~mm}$. 


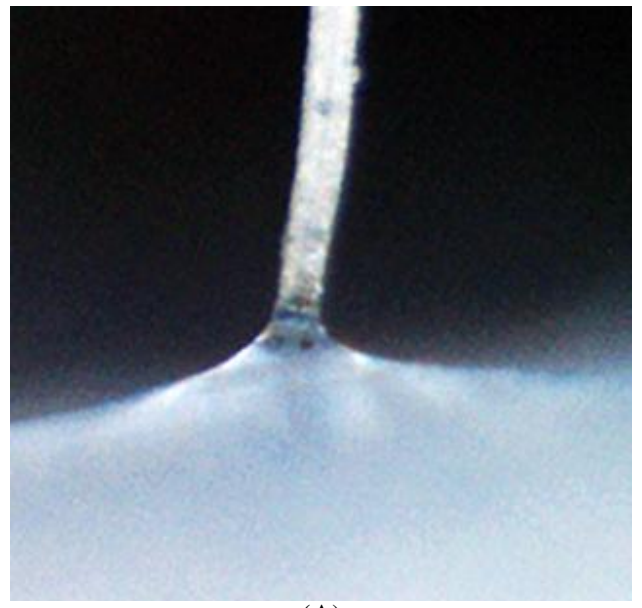

(A)

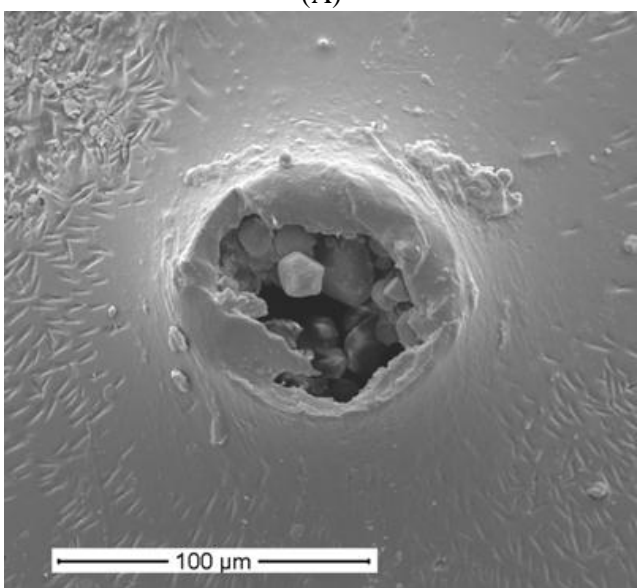

(B)

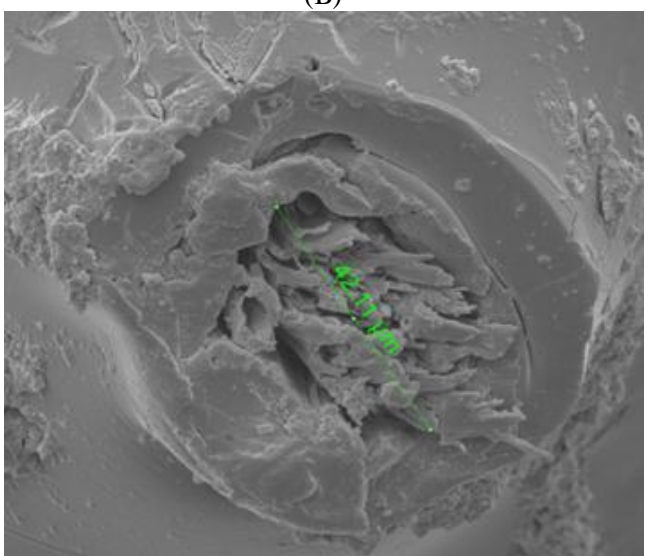

(C)

Fig. 3. Pull out test result: (A). Fiber embedded in matrix (optical image); (B) Fiber debonding; (C) Fiber fracture

Table 1 shows the values of the critical fiber length for other fibers used as reinforcement. The high strength synthetic aramid, glass and carbon fibers have smaller critical lengths than lignocellulosic fibers, whenever a strong interface is developed. This is a direct consequence of the dependence of the matrix to fiber load transfer on the fiber modulus to matrix modulus ratio.
The fiber length is strongly influencing properties of the composites and has a significant role in the fracture strength of short fiber reinforced composites. The maximum stress level in the fiber was able to achieve if the fiber length should be equal or greater than the critical fiber length that explained as a minimum fiber length required for the stress to attain the fracture stress of fiber. It has been declared that fiber length in the composites with a value less than $5 l_{c}$ has lower strength than that of a continuous fiber in the similar fiber volume fraction. The short fiber reinforced composite strength enhances with fiber length above $10 l_{c}$. So, it is very important for optimizing the fibre length in the fibre reinforced composite system, so the optimum properties is able to be obtained [19]. Thus smaller critical fibre length, better interfacial properties [20].

TABLE I. COMPARATION OF BOTH SHEAR STRENGTH AND CRITICAL LENGTH OF FIBER IN POLYMER COMPOSITE

\begin{tabular}{|c|c|c|c|c|c|}
\hline Fiber & Matrix & Methods & $\begin{array}{l}\text { Shear } \\
\text { strength } \\
(\mathrm{MPa})\end{array}$ & $\begin{array}{l}\text { Critical } \\
\text { length } \\
(\mu \mathrm{m})\end{array}$ & $\begin{array}{l}\text { Refe- } \\
\text { rence }\end{array}$ \\
\hline Mendong & Epoxy & Pullout & 11 & 630 & Test \\
\hline Piassava & $\begin{array}{l}\text { Polyes } \\
\text { ter }\end{array}$ & Pullout & $1.9-2.8$ & 15000 & [21] \\
\hline Banana & $\begin{array}{l}\mathrm{PF} \\
\text { resin }\end{array}$ & Pullout & 44 & - & [22] \\
\hline Hemp & $\begin{array}{l}\mathrm{PP}+ \\
\text { MAPP }\end{array}$ & $S F F T$ & 15,4 & 830 & [23] \\
\hline Ramie & Epoxy & Pullout & 16,5 & 302 & [24] \\
\hline Ramie & PP & $S F F T$ & 24,9 & 980 & [25] \\
\hline Flax & Epoxy & $\begin{array}{r}\text { Micro- } \\
\text { bond }\end{array}$ & 22,7 & - & [26] \\
\hline Flax & $\begin{array}{l}\mathrm{PP}+ \\
\mathrm{MAPP}\end{array}$ & & 12 & 820 & [13] \\
\hline Cotton & PP & Pullout & 0.7 & 5000 & [13] \\
\hline Carbon & PP & Pullout & 18.2 & 810 & [21] \\
\hline Glass & $\mathrm{PP}$ & Pullout & 15.2 & 890 & [21] \\
\hline
\end{tabular}

The aspect ratio of the fiber is the ratio of the minimum fibers length to its cross-sectional diameter in which the maximum remissible stress of fiber can be reached out for a given load. Mendong fiber embedded in epoxy composite has critical aspect ratio of 12.6. For many fiber-polymer composite system is in the range of 10 to 50 [27]. Fiber length is important to develop maximum tensile properties in the composite.

Aspect ratio parameters are determined not only by matrix and fiber properties but also by the interface quality between fiber and matrix. The load is transferred from matrix to fiber through shear stress along the interface of fiber-matrix so that for gaining a maximum reinforcement, the aspect ratio of fiber in the composite system must be over its critical value. This will ensure maximum stress shift in the composite fiber before it fails. If the aspect ratio of fibers is lower than the critical value then the stress is not transferred enough so that the fiber will be inefficient or not receive the maximum stress that can be withheld. Conversely, if the aspect of the fiber ratio is too high then it can cause problems with fiber dispersion in the matrix [28]. 


\section{CONCLUSION}

Evaluation of critical fiber length of mendong fiber embedded in epoxy composite was done. Mendong fiber has a low critical fiber length $(0.63 \mathrm{~mm})$ in epoxy matrix composite. In the future, for applying mendong fiber as reinforcement in epoxy composite, the particle-shaped of mendong fibers is more feasible for easeness in both fiber extraction process and composite processing.

\section{ACKNOWLEDGMENT}

This research has supported by the Ministry of Research, Technology and Higher Education of Republic of Indonesia through the scheme of the Fundamental Research Program 2016.

\section{REFERENCES}

[1] X. Li, L. G. Tabil, and S. Panigrahi, "Chemical Treatments of Natural Fiber for Use in Natural Fiber-Reinforced Composites: A Review," J. Polym. Environ., vol. 15, no. 1, pp. 25-33, Jan. 2007.

[2] Q. Mu, C. Wei, and S. Feng, "Studies on Mechanical Properties of Sisal Fiber / Phenol Formaldehyde Resin In-Situ Composites," Polym. Compos., vol. 30, pp. 131-137, 2009.

[3] Mohanty, M. Misra, and L. T. Drzal, "Natural fibers, biopolymers, and biocomposites: an introduction," in Natural fibers, biopolymers, and biocomposites., Taylor and Francis Publisher, 2005, pp. 1-36.

[4] E. de Jong, A. Higson, P. Walsh, and M. Wellisch, "Product developments in the bio-based chemicals arena," Biofuels, Bioprod. Biorefining, vol. 6, no. 6, pp. 606-624, Oct. 2012.

[5] H. Suryanto, S. Solichin, and U. Yanuhar, "Natural Cellulose Fiber from Mendong Grass (Fimbristylis globulosa)," in Fiber Plants - Biology, Biotechnology and Applications, 1st ed., K. G. Ramawat and M. R. Ahuja, Eds. Springer, 2016, pp. 1-17.

[6] H. Suryanto, E. Marsyahyo, Y. S. Irawan, and R. Soenoko, "Morphology, Structure, and Mechanical Properties of Natural Cellulose Fiber from Mendong Grass (Fimbristylis globulosa),"J. Nat. Fibers, vol. 11, no. 4, pp. 333-351, Jul. 2014.

[7] D. Heim, M. Hartmann, J. Neumayer, C. Klotz, Ö. Ahmet-T saous, S. Zaremba, and K. Drechsler, "Novel method for determination of critical fiber length in short fiber carbon/carbon composites by a double lap joint," Compos. Part B Eng., vol. 54, no. 1, pp. 365-370, 2013.

[8] H. Suryanto, Y. S. Irawan, E. Marsyahyo, and R. Soenoko, "Effect of Alkali Treatment on Crystalline Structure of Cellulose Fiber From Mendong (Fimbristylis globulosa) Straw,” Key Eng. Mater., vol. 594595, pp. 720-724, 2014.

[9] H. Suryanto, E. Marsyahyo, Y. S. Irawan, R. Soenoko, and Aminudin, "Improvement of Interfacial Shear Strength of Mendong Fiber (Fimbristylis globulosa) Reinforced Epoxy Composite Using the AC Electric Fields," International J. Polym. Sci., vol. 2015. pp. 1-10, 2015.

[10] H. Suryanto, Y. Irawan, R. Soenoko, P. Puspitasari, and Aminnudin, "The Effect of the Electric Fields on Crystalline Structure and Functional Group of Mendong Fiber (Fimbristylis globulosa)," in Proceedings of the Mechanical Engineering and En gineering Education Conferences, 2016, vol. 1778, pp. 30007-1-30007-5.

[11] A. V. Gonzalez, J. M. Cervantes, R. Olayo, and P. J. H. Franco, "Effect of fiber surface treatment on the fiber-matrix bond strength of natural fiber reinforced composites," Compos. Part B Eng., vol. 30, no. 3, pp. 309-320, Apr. 1999.

[12] Tsai and K.-S. Kim, "The Micromechanics of Fiber Pull-Out," J.Mech.Phys Solid, vol. 44, no. 7, pp. 1147-1177, 1996.

[13] K. L. Pickering, M. G. A. Efendy, and T. M. Le, "A review of recent developments in natural fibre composites and their mechanical performance,”Compos. Part A Appl. Sci. Manuf., vol. 83, pp. 98-112, 2016.

[14] C. C. Guo, Y. Zhao, D. Chen, and M. S. Zhan, "Effect of sizing agent on the interfacial shear strength of carbon fibre composites," Mater. Res. Innov., vol. 18, no. sup4, pp. S4-997-S4-1002, Jul. 2014.

[15] J. M. He and Y. D. Huang, "Effect of silane-coupling agents on interfacial properties of CF/PI composites," J. Appl. Polym. Sci., vol. 106, no. 4, pp. 2231-2237, Nov. 2007.

[16] M. H. Choi, B. H. Jeon, and I.. Chung, "The effect of coupling agent on electrical and mechanical properties of carbon fiber/phenolic resin composites,"Polymer (Guildf)., vol. 41, no. 9, pp. 3243-3252, Apr. 2000.

[17] T. J. Keener, R. K. Stuart, and T. K. Brown, "Maleated coupling agents for natural fibre composites," Compos. Part A Appl. Sci. Manuf., vol. 35, no. 3, pp. 357-362, Mar. 2004.

[18] Z. Li, S. Wu, Z. Zhao, and L. Xu, "Influence of surface properties on the interfacial adhesion in carbon fiber/epoxy composites," Surf. Interface Anal., vol. 46, no. 1, pp. 16-23, Jan. 2014.

[19] S. Joseph, M. Sreekala, Z. Oommen, P. Koshy, and S. Thomas, “A comparison of the mechanical properties of phenol formaldehyde composites reinforced with banana fibres and glass fibres," Compos. Sci. Technol., vol. 62, pp. 1857-1868, 2002.

[20] D. I. Shah, P. J. Schubel, P. Licence, and M. J. Clifford, “Determining the minimum, critical and maximum fibre content for twisted yarn reinforced plant fibre composites," Compos. Sci. Technol., vol. 72, no. 15, pp. 1909-1917, Oct. 2012.

[21] R. C. M. P. Aquino, S. N. Monteiro, and J. R. M. D'Almeida, "Evaluation of the critical fiber length of piassava (Attalea funifera) fibers using the pullout test,” J. Mater. Sci. Lett., vol. 22, no. 21, pp. 1495-1497, 2003.

[22] S. Joseph, M. S. Sreekala, Z. Oommen, P. Koshy, and S. Thomas, “A comparison of the mechanical properties of phenol formaldehyde composites reinforced with banana fibres and glass fibres," Compos. Sci. Technol., vol. 62, pp. 1857-1868, 2002.

[23] G. W. Beckermann and K. L. Pickering, "Composites : Part A Engineering and evaluation of hemp fibre reinforced polypropylene composites: Micro-mechanics and strength prediction modelling," Compos. Part A, vol. 40, no. 2, pp. 210-217, 2009.

[24] E. Marsyahyo, "Perlakuan Permukaan Serat Rami (Boehmeria nivea) dan Kompatibilitas Serat - Matrik Pada Komposit Matrik Polimer.," Disertasi. Univ. Gadjah Mada., 2009.

[25] A. Awal, G. Cescutti, S. B. Ghosh, and J. Müssig, “Composites : Part A Interfacial studies of natural fibre / polypropylene composites using single fibre fragmentation test ( SFFT )," Compos. Part A, vol. 42, no. 1, pp. 50-56, 2011.

[26] C. Baley, F. Busnel, Y. Grohens, and O. Sire, "Influence of chemical treatments on surface properties and adhesion of flax fibre-polyester resin,” Compos. Part A Appl. Sci. Manuf., vol. 37, no. 10, pp. $1626-$ 1637, Oct. 2006.

[27] P. Morgan, Carbon fibers and their composites. Taylor \& Francis, 2005.

[28] D. J. Lee and S. R. Ryu, "The Influence of Fiber Aspect Ratio on The Tensile and Tear Properties of Short-Fiber Reinforced Rubber," in ICCM12proceedings, 1999. 